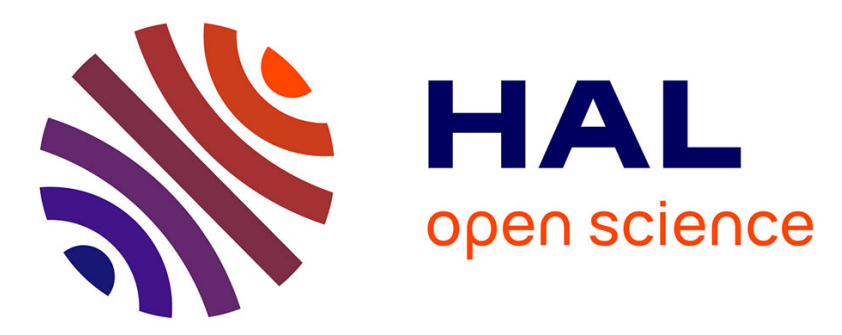

\title{
The Empirical Merit of Structural Explanations of Commodity Price Volatility: Review and Perspectives
}

Nicolas Legrand

\section{To cite this version:}

Nicolas Legrand. The Empirical Merit of Structural Explanations of Commodity Price Volatility: Review and Perspectives. Journal of Economic Surveys, 2019, 33 (2), 10.1111/joes.12291 . hal01924388

\section{HAL Id: hal-01924388 \\ https://hal.science/hal-01924388}

Submitted on 15 Nov 2018

HAL is a multi-disciplinary open access archive for the deposit and dissemination of scientific research documents, whether they are published or not. The documents may come from teaching and research institutions in France or abroad, or from public or private research centers.
L'archive ouverte pluridisciplinaire HAL, est destinée au dépôt et à la diffusion de documents scientifiques de niveau recherche, publiés ou non, émanant des établissements d'enseignement et de recherche français ou étrangers, des laboratoires publics ou privés. 


\title{
The Empirical Merit of Structural Explanations of Commodity Price Volatility: Review and Perspectives*
}

\author{
September 3, 2018
}

\begin{abstract}
This paper presents both the history of and state-of-the-art in empirical modeling approaches to the world commodity price volatility. The analysis builds on the storage model and key milestones in its development. Specifically, it is intended to offer a reader unfamiliar with the relevant literature an insight into the modeling issues at stake from both a historical and speculative viewpoint. The review considers primarily the empirical techniques designed to assess the merits of the storage theory; it does not address purely statistical approaches that do not rely on storage theory and which have been studied in depth in other streams of the commodity price literature. The paper concludes with some suggestions for future research to try to resolve some of the existing empirical flaws, and hopefully to increase the explanatory power of the storage model.
\end{abstract}

Keywords: Commodity price dynamics, storage model, empirical validation, structural econometrics.

${ }^{*}$ I would like to thank the co-editor and two anonymous referees for very insightful comments and suggestions. Thanks also to Christophe Gouel and Alexandre Gohin for their helpful remarks. The author only is responsible for any omissions or deficiencies. 


\section{Introduction}

The recent recurring wild boom and bust cycles in global commodity markets have hit the headlines and are high on political agendas. There is a host of effective causes behind this extreme volatility which have potential conflicting implications for policy. Since different determinants entail different treatments, the related policy guidance and normative analyses need to rely on a sound model featuring the economic mechanisms underlying the formation of commodity prices. It should include also the main drivers of the observed dynamics, and the way external shocks propagate through the system. Finally, it needs to be both empirically relevant in order to account for the majority of the patterns observed in the data, and transparent in the sense of allowing a clear understanding of the interdependence among the variables involved, and the potential effects of a given policy. In simple terms, there is a trade-off between the complexity and readability, and internal and external consistency of the model with the emphasis on one or other features depending on the policy being implemented and its objectives.

A candidate model in the context of unstable prices in world commodity markets is the competitive storage model with rational expectations, whose foundations were laid in Gustafson (1958). In essence, the competitive storage model is a basic supply and demand, dynamic stochastic equilibrium commodity market model which positions storers center stage. Speculative demand for storage, by absorbing and spreading exogenous disturbances to the market, plays a key mediating role in the implied price dynamics. This is not to say that storage theory is the only way to consider commodity price volatility and stabilization policies. ${ }^{1}$ However, it has become a cornerstone of empirical studies dealing with price fluctuations in the global markets for primary products and has led to in-depth studies of the storage model, its interactions with trade, and its final implications for overall price dynamics including Wright and Williams (1982, 1984) which are summarized in Williams and Wright (1991). Furthermore, in an effort to achieve a more realistic modeling, several authors have proposed extensions to account for persistent or intra-seasonal shocks e.g. Lowry et al. (1987), Chambers and Bailey (1996), Ng and Ruge-Murcia (2000), and Osborne (2004) among others.

The aim of this paper is to provide a summary of the state-of-the-art in empirical approaches to modeling world commodity price volatility by placing the storage model at the heart of the analysis. Specifically, the objective is to offer readers unfamiliar with this literature a gist of the modeling issues at stake from both a historical and prospective viewpoint. The literature on storage models is vast; here, I focus on the empirical techniques designed to assess the merits of storage theory. I deliberately ignore purely statistical approaches that do not rely on economic theory and which have been thoroughly studied in other works such as Labys (2006)'s textbook.

As I have suggested, the usefulness of any economic model needs to be evaluated in light of its performance with respect to both internal and external consistency. From this perspective, the achievements of the storage model and the associated theory are rather mixed. On the one hand, in many respects its success regarding internal consistency cannot be disputed; the model is parsimonious and theoretically grounded in clear mechanics. On the other hand, the model's

\footnotetext{
${ }^{1}$ Traditionally, the opposite view would be to consider that price fluctuations originate from agents' forecasting errors as posited by the cobweb theorem (Ezekiel, 1938). A comprehensive survey of the opposition between the storage and cobweb models literature and their associated policy implications can be found in Gouel (2012).
} 
external consistency was challenged in the early structural estimations published in Deaton and Laroque (1996). At that time, the empirical approach developed for a full test of storage theory against the observed price data was as innovative as the conclusions were disappointing. The model version that was tested failed to match the typical high levels of serial correlation observed in real price data. ${ }^{2}$ Just a decade later, Cafiero and Wright (2006) pointed to several pitfalls of various kinds-e.g., empirical, theoretical and numerical-in this estimation procedure which if resolved might improve its explanatory power. Since then, and with the benefit of a further round of mathematical and computational advances, these same authors have addressed most of the previously identified failures of the storage model, and especially the lack of induced persistence in prices. This in turn, has led to a restatement of the empirical relevance of storage theory. That said, autocorrelation is not the only aspect of commodity price behavior that the storage model struggles to match. Chief among these is perhaps the excessive correlations across commodity and other asset prices which Pindyck and Rotemberg (1990) describes as the "excess of co-movements" puzzle. Therefore, the time seems ripe to provide a review of the empirical economic literature dealing with commodity price volatility using a storage theory lens.

Section 2 reviews the variety of empirical strategies that have been employed to test the implications of storage theory on the prices behavior, and then in a more structural way, to take the storage model directly to the data. This makes it feasible to highlight the key developments so far, and point out those dimensions where it performs less well. Section 3 then discusses the opportunities for improving the model fit through the introduction of persistent demand factors and other macroeconomic spillover effects through the respective exchange rate and interest rate channels. Section 4 summarizes the main results and suggests avenues for further research in this field which could cover different time horizons and embed potential solutions to both resolve the main obstacles and improve the model's overall explanatory power.

\section{Empirical performance of the competitive storage model}

\subsection{Which stylized facts to match?}

Before assessing the empirical merit of a given model, it is worth recalling some key features about commodity prices which the modeling is supposed to explain. Table 1 presents some of these stylized facts using the annual price series for thirteen commodities proposed by Deaton and Laroque (1992) and which most subsequent empirical analyses employ. ${ }^{3}$

The first two columns in table 1 show that commodity prices are highly persistent with first-and second-order coefficients of autocorrelation always in excess of .8 and .6 respectively, except for sugar. Also typical is the substantial volatility of these prices with yearly variations often close to $50 \%$ and sometimes even higher for products such as cocoa, palm oil, or sugar. In the higher moments of the price distribution, with the exception of bananas and tea all the series are positively skewed meaning there are no equally prominent price troughs matching

\footnotetext{
${ }^{2}$ Recall that the transfer of inventories from one period to the next is the unique source of persistence in prices provided that the shocks to the system are assumed to be identically and independently distributed (i.i.d.) following a normal distribution.

${ }^{3} \mathrm{~A}$ full description of the data is provided in Pfaffenzeller et al. (2007) and regular updates of the price indexes are available from Stephan Pfaffenzeller's personal website (http://www.stephan-pfaffenzeller.com).
} 
Table 1: Commodity price facts 1900-2011

\begin{tabular}{lcccrr}
\hline Commodity & $\begin{array}{c}\text { One-year } \\
\mathrm{a}-\mathrm{c}\end{array}$ & $\begin{array}{c}\text { Two-year } \\
\mathrm{a}-\mathrm{c}\end{array}$ & $\begin{array}{c}\text { Coefficient } \\
\text { of variation }\end{array}$ & Skewness & $\begin{array}{r}\text { Excess } \\
\text { kurtosis }\end{array}$ \\
\hline Banana & 0.95 & 0.90 & 0.23 & -0.27 & -0.77 \\
Cocoa & 0.86 & 0.71 & 0.60 & 1.24 & 1.64 \\
Coffee & 0.84 & 0.68 & 0.50 & 1.61 & 3.89 \\
Copper & 0.83 & 0.64 & 0.40 & 0.90 & 0.56 \\
Cotton & 0.94 & 0.85 & 0.51 & 0.20 & -0.61 \\
Jute & 0.84 & 0.70 & 0.44 & 0.41 & -0.23 \\
Maize & 0.86 & 0.73 & 0.51 & 0.84 & 1.22 \\
Palm oil & 0.82 & 0.65 & 0.60 & 2.43 & 11.84 \\
Rice & 0.91 & 0.79 & 0.50 & 0.42 & -0.39 \\
Sugar & 0.70 & 0.51 & 0.69 & 1.62 & 3.45 \\
Tea & 0.90 & 0.81 & 0.38 & -0.02 & -0.80 \\
Tin & 0.90 & 0.78 & 0.47 & 1.48 & 2.84 \\
Wheat & 0.91 & 0.79 & 0.47 & 0.82 & 0.39 \\
\hline
\end{tabular}

Notes: The data conform to the series in Deaton and Laroque (1992) but are extended consistently to 2011. Real annual price indexes are obtained by averaging the monthly price data provided by the World Bank Development Prospects Groups over the calendar year, normalizing them with respect to the 1977--79 mean price, and then deflating them by the US Consumer Price Index (CPI).

the spikes. Also, the last column of table 1 shows that most of the price distributions have fat tails underlining the greater likelihood of extreme values. In sum, a consistent model must account for alternating asymmetric boom and bust cycles and long periods of relatively low and stable prices interspersed with clusters of episodes of higher volatility during which steep price jumps are followed almost immediately by similarly sharp reversions toward the mean. All of these elements are among the most prominent empirical features of commodity prices. To account for these characteristics, the time series modeling strategies in the class of ARMA and GARCH-type models have trouble matching both the conditional heteroskedasticity and high levels of persistence in prices along with the positive skewness and kurtosis, unless leaving these higher moments being accounted for by the innovation terms. Also problematic are the alternative models derived from the random walk theory which, while parsimonious and able to provide a good fit for some commodities, are based on the assumption that all price variations be permanent. This is at odds with the alternating boom and bust cycles along with mean-reverting process evident in the price data of many commodities, and especially those for which the weather plays a major role in driving the price dynamics on the market. This calls for the use of structural modeling techniques attempting to explain price fluctuations from the market fundamentals through a basic supply and demand equilibrium framework subjects to random shocks.

In this context, the workhorse structural model in empirical research on commodity price volatility is the rational expectations competitive storage model with a non-negativity constraint on inventories, justified on the grounds that it is impossible to store something that has not yet been produced. The standard version consists of a partial equilibrium model of the international 
commodity market in which $(i)$ production is annual, inelastic and follows a normal i.i.d. process, ${ }^{4}$ (ii) consumption demand is linear, and (iii) prices are mediated by speculative demand from storers. Following the common strategy of buying low and selling high, storage activity transfers units of production from years of abundance to years of scarcity, thus smoothing prices and creating the aforementioned positive autocorrelation. Having said this, such buffering effect of storage on prices vanishes upon stockouts leading to a market much more sensitive to supply and demand shocks and episodes of high price volatility. The resulting conditional heteroskedasticity varying with the storage levels is well observed in the data. Furthermore, the storage mechanism also implies the typical asymmetries in price fluctuations, since in the event of abundant supply, demand for storage mitigates price troughs but cannot prevent price surges whenever inventories are empty. Finally, the abnormally high occurrence of large price hikes translates in the measured leptokurtic price distribution.

Turning to the model's equations, the crucial non-negativity constraint on stocks depicts two regimes for the price process provided inventories are held, i.e. whenever speculators expect sufficiently high future selling prices to cover the interest and storage charges incurred to carry inventories in the next period. The storage arbitrage condition can be written as:

$$
\beta(1-\delta) \mathrm{E}_{t} P_{t+1}-P_{t}-k \leq 0,=0 \text { if } S_{t}>0,
$$

where $\beta=1 /(1+r)$ is the discount factor which is assumed to be fixed, $\delta \geq 0$ is the depreciation rate of inventories, $k \geq 0$ is the constant per-unit physical cost of storage, $P_{t}$ is the price, and $\mathrm{E}_{t}$ is the expectation operator conditional on period $t$ information. The model is closed by two other equations. The first is the market clearing condition stating that every period supply equals total demand:

$$
A_{t}=S_{t}+D\left(P_{t}\right)
$$

where $A_{t}$ is the availability at time $t$. The second describes the evolution of the state variable $A_{t}$ over time, written as the sum of the past inventories and the stochastic production $\epsilon_{t}$ :

$$
A_{t} \equiv(1-\delta) S_{t-1}+\epsilon_{t}
$$

The attempts to test storage theory by bringing the storage model to the data follow the two common reduced-form and structural empirical approaches.

\subsection{Limited-information estimation techniques}

The first class of econometric methods relies on choosing a set of restrictions imposed by the economic theory of storage, and then inspecting if they really are reflected in the data.

\footnotetext{
${ }^{4}$ There are several reasons for this modeling decision. First, to deal with identification issues in the context of inference made on prices alone because of lack of information on quantities. Second, Deaton and Laroque $(1992,1996)$ adopt this type of modeling to justify this basic supply-side specification which was standard in the commodity storage literature at the time. Third, most subsequent empirical studies followed Deaton and Laroque's research path and maintained these same modeling restrictions, notably to ease comparability among estimations results. However, although appropriate in the context of agricultural products, these hypotheses are more dubious in studies of price dynamics in non-agricultural commodities which led to the development of more complex intra-year versions of the storage model that relaxed a part or all of these historical restrictions (Lowry et al., 1987; Chambers and Bailey, 1996; Osborne, 2004).
} 
For instance, Deaton and Laroque (1992) provide a generalized method of moments (GMM) procedure adapted from Hansen and Singleton (1982) to estimate the basic competitive storage model with inelastic supply and without storage costs. Resting on the rational expectations assumption exemplified in the Euler equation (1), they show the existence of a constant threshold price $P^{*}$ above which storage is no longer profitable. As a result they define an autoregressive process for the equilibrium price function in the form

$$
\mathrm{E}_{t} P_{t+1}=\gamma\left[\min \left(P_{t}, P^{*}\right)+k\right]
$$

with $\gamma=1 / \beta(1-\delta)$. Hence, the price regime implied by the model is either a stationary process with mean $P^{*}$, or an autoregressive process with coefficient $\gamma$ whenever the actual price falls below the threshold $P^{*}$. The first moment condition (4) written as $u_{t}=P_{t}-\gamma\left[\min \left(P_{t-1}, P^{*}\right)+k\right]$ makes it feasible to derive the following GMM criterion, $u^{\prime} W\left(W W^{\prime}\right)^{-1} W^{\prime} u$, where $u_{t}$ is a stationary series of innovations which given the hypothesis of rational expectations effectively holds, and is uncorrelated to a given matrix $W$ of the instrumental variables known at time $t-1$ and earlier. Relying on the annual prices of thirteen primary products, the authors estimate $\gamma$ and $P^{*}$ using a constant and lagged one-to-three prices as instruments, and find mixed results. Interestingly, the price simulations implied by the calibrated model display most of the essential patterns observed in the actual price series such as alternating boom and bust periods, heteroskedasticity, positive skewness, and fatter tails. Furthermore, the high values of the estimated cut-off price $P^{*}$ entails that between $77 \%$ to $99 \%$ of the time is within an active storage regime, thereby fostering the positive autocorrelation induced by the model. Deaton and Laroque's chief concern is that the simple storage mechanism does not capture most of the serial time dependency since with values ranging between 0.21 and 0.48 , the first-order autocorrelation coefficients of the simulated prices reach barely half of the true ones. In an attempt to check the validity of the inference procedure, they perform autocorrelation tests on the residuals on the assumption that if the storage model fails to match the actual high degrees of serial correlation, the unexplained autocorrelation should be found in the residuals $u_{t}$. However, both the overidentification and the Durbin-Watson tests conducted on the residuals lead to rejection of the hypothesis of serially correlated residuals, and thus, to the conclusion that there seems to be no excess serial correlation left unaccounted for by the autoregression equation (4). This tends to qualify the authors' pessimistic conclusions.

In the footsteps of Deaton and Laroque (1992), a growing literature soon emerged to assess the empirical relevance of the storage theory. Table 2 presents a summary of the main takeaways from the most important empirical studies on the storage model highlighting what they explain and in which dimensions they fail. Still in the spirit of using reduced-form empirical methods to verify the storage theory, $\mathrm{Ng}$ (1996) exploits the implied switching regime of the price dynamics around $P^{*}$ by fitting the data with a Self-Exciting Threshold Autoregressive (SETAR) model (Tong and Lim, 1980). Interestingly, this set-up allows identification of which aspect of the storage theory is rejected by the data, which the GMM procedure does not. Basically, the approach relies on the fact that the price process must exhibit two different stochastic properties depending on whether it lies above or below the cut-off. More precisely, once the price exceeds the threshold $P^{*}$, it is given only by the inverse demand function so that the price evolves 
Table 2: The key empirical studies of the commodity storage model

\begin{tabular}{llc}
\hline \multicolumn{1}{c}{ Study } & \multicolumn{1}{c}{ Data } & Specification \\
\hline Nonstructural methods & & \\
$\begin{array}{l}\text { Deaton and Laroque (1992) } \\
(\text { D\&L(92)) }\end{array}$ & 13 commodities, & GMM on the Euler \\
& WB spot prices, & storage equation \& \\
& annual, 1900-87 & MC experiments
\end{tabular}

Ng and Pirrong (1994)

$\operatorname{Ng}(1996)$

Routledge et al. (2000)

Beck (2001)

Cafiero et al. (2011)

Cafiero et al. (2015)

Guerra et al. (2015)

Gouel and Legrand (2017a)

Structural methods

Deaton and Laroque (1996)

As in D\&L(92)

WTI Crude Oil, NYMEX futures,

1-10 month to delivery, monthly, 1992-96

20 commodities $^{* *}$, CRB spot prices, annual, 1840-1996 5 metals incl. silver*, \& 3-month futures

As in D\&L(92)

As in D\&L(92)

Sugar price index, WB spot price, annual, 1921-2009

WB Corn price, $8 \neq$ spot price indexes, annual, 1942-2012

As in D\&L(92) extended up to 2011
Dynamic ECM to test 6 theoretical pred. of past spread effects

$$
\begin{aligned}
& \text { SETAR model } \\
& \text { to test for a } \\
& \text { regime-dependent } \\
& \text { price behavior }
\end{aligned}
$$

Efficient calib. of the structural model to fit cond. \& uncond. price volatilities

$3 \neq$ GARCH-type models to test for $\mathrm{ARCH}$ process in prices
Fit nonlinearities, cond. variances, asymmetries, but lack of persistence

Signif. effects on var. \& covar. of spot/Fwd returns

Mixed, i.e. signif. autoreg. coeff. also in the stockout regime

Consistent pred. of Fwd volatilities incl. violations of the Samuelson effect

Signif. ARCH(1) effects only w/ storable products

Fail to fit the high persistence levels w/o i.i.d. shocks cond. expectations and variances of prices

D\&L(96)'s PML with cst. marg. storage cost $\& \uparrow$ numerical accuracy in the model resolution

Full-Information
ML estimation

FIML estimator testing $8 \neq$ averaging methods

FIML augmented $\mathrm{w} / \mathrm{o}$ det. trends
Fit cond. moments, $\uparrow$ serial correlation, but no stockouts

Good overall fit, plausible estimates $\&$ nb. of stockouts

Signif. averaging bias, better fit w/ single month/year

$\mathrm{W} /$ trends: $\uparrow \mathrm{AIC}$, more plausible param. values \& nb. of stockouts

Signif. \& robust estimates validate the storage-based estimation strategy
Instrumental methods

Roberts and Schlenker (2013) Caloric aggregate of grains \& soybeans, WB spot price, annual, 1960-2007
3-SLS w/ past yield shocks as IV to identify separately $\mathrm{S} \& \mathrm{D}$ elasticities

(*) These are aluminum, copper, lead and zinc traded on the London Metal Exchange.

(**) The list includes both storable and non-storable commodities taken from the CRB Commodity Yearbook or the USDA with sample lengths varying with the commodity. See the paper for a full description of the data. 
according to the supply process which is assumed to be normally and identically distributed. As previously noted, when inventories are carried over the price follows a first-order autoregressive process and the conditional moments lose their Gaussian nature. For instance, the conditional variance of prices becomes heteroskedastic because the volatility is increasing with the price level since there are fewer stocks available to buffer against a production shortage. ${ }^{5}$ Using the quasi-maximum likelihood estimator and the same dataset as in Deaton and Laroque (1992), the author estimates a $\operatorname{SETAR}(r, d, c, q)$ model of the form

$$
\begin{aligned}
& P_{t}=a_{1}+\rho_{1} P_{t-1}+e_{1 t} \text { if } S_{t}>0, \\
& P_{t}=a_{2}+\rho_{2} P_{t-1}+e_{2 t} \text { otherwise, }
\end{aligned}
$$

where the threshold value $c$ is $P^{*}$, and the number of thresholds $r$, the delay parameter $d$, and the order of the autoregression $q$ are all equal to 1 as dictated by the theory which also imposes the testable restrictions $\rho_{1}>0$ and $\rho_{2}=0$. Another assumption, albeit not one implied by storage theory but which can be tested from (5) is the market efficiency condition given by $a_{1}+\rho_{1} P^{*}=a_{2}+\rho_{2} P^{*}$. From the estimation results obtained without imposing the market efficiency condition, $\mathrm{Ng}$ concludes that all of the conditional mean prices, and the variances for all the commodities except tea, cocoa, and rice are lower when storage is active, as predicted by the theory. In addition, although most commodity prices show the expected significant persistence in the stockholding regime (e.g., $\rho_{1}>0$ ), the latter state-dependency remains significant in the stockout situation (e.g., $\rho_{2} \neq 0$ ), something that clearly contradicts the underlying theory. ${ }^{6}$ In fact, only 4 out of the 13 commodity price series provide full support for the theory. Notwithstanding this, and in line with Deaton and Laroque (1992), the author also finds low frequency of stockout episodes, and underlines that this tends to reduce not only the precision in the identification of the parameters of the second autoregression in (5) but also the robustness of the standard significance test for the null $\rho_{2}=0$ since this is based on a very limited number of observations which fall into the stockout regime. Ng acknowledges this and infers that when stocks are empty prices are autocorrelated if the absolute value of $\rho_{2}$ is substantially greater than zero. Overall, the speculative storage theory cannot be rejected on the basis solely of a statistically significant autoregressive coefficient $\rho_{2}$.

In subsequent work, Beck (2001) completes the empirical analysis by conducting statistical tests for the significance of volatility clustering in the distribution of commodity prices. This also is a key characteristic implied by the speculative storage activity which by reallocating production across time, creates a channel for the transmission of the price volatility over time. ${ }^{7}$ In statistical terms, this means that the price variance should be state-dependent. From an econometric standpoint, the author relies on generalized autoregressive conditionally heteroskedastic-type models $((\mathrm{G}) \mathrm{ARCH}(p, q))$ to capture the potential time-varying volatility clustering manifested in the residuals of the autoregressive models estimated on commodity prices. The general

\footnotetext{
${ }^{5}$ The author ignores the heteroskedasticity issue in noting that it affects only the efficiency property of a given estimator which otherwise, remains consistent.

${ }^{6}$ Imposing the market efficiency restriction does not change the overall conclusion since the patterns of serial correlation in prices are found in both regimes.

${ }^{7}$ This link being either broken when there is a stockout, or irrelevant if the commodity is not storable.
} 
expression of the estimated model is

$$
\begin{aligned}
P_{t} & =\alpha+\beta t+\sum_{i=1}^{p} \rho_{i-1} P_{t-i}+e_{t}, \\
& =\alpha+\beta t+\sum_{i=1}^{p} \rho_{i-1} P_{t-i}+e_{t}^{d}-e_{t}^{s},
\end{aligned}
$$

where the error term $e_{t}$ is the combination of a demand and a supply shock assumed i.i.d. with zero means and variances respectively denoted $\sigma_{\epsilon^{d}}^{2}$ and $\sigma_{\epsilon^{s}}^{2}$, and drawn from a stationary distribution. ${ }^{8}$ Though both of the external shocks are homoskedastic, the author shows that the resulting price variance $\sigma_{\epsilon}^{2}$ is not constant, and depends on its lagged values. ${ }^{9}$ It appears that $e_{t}=\eta_{t} \sqrt{h_{t}}$, where $\eta_{t}$ is a white noise and $h_{t}$ is the expected price variance conditional on past values $e_{t-i}$. In a first step, $h_{t}$ is assumed to follow an autoregressive moving average $((\operatorname{ARMA}(p, q))$ process such that:

$$
h_{t}=a_{0}+\sum_{j=1}^{p} a_{j} \sigma_{e_{t-j}}^{2}+\sum_{k=1}^{q} b_{k} h_{t-k}
$$

Another testable prediction of the theory is the response of prices to external supply and demand shocks which should vary whether or not the non-negativity constraint on inventories is binding. Indeed, high prices are expected to be more volatile since few or no inherited inventories can be used to smooth price changes. Thus, times of high (low) price volatility should be associated with positive (negative) shocks to the price level. The exponential-GARCH model (EGARCH) can be used to characterize this phenomenon and is obtained by rewriting (7) as follows:

$$
\ln \left(h_{t}\right)=a_{0}+\sum_{i=1}^{p} a_{1 i}\left(\frac{e_{t-i}}{\sqrt{h_{t-i}}}\right)+\sum_{i=1}^{p} a_{2 i}\left(\left|\frac{e_{t-i}}{\sqrt{h_{t-i}}}\right|-\mathrm{E}\left|\frac{e_{t-i}}{\sqrt{h_{t-i}}}\right|\right)+\sum_{j=1}^{q} b_{j} \ln \left(h_{t-j}\right)+u_{t},
$$

where the $a_{1 i}$ and $a_{2 i}$ parameters account respectively for the asymmetry and the ARCH process. Assuming a first-order ARCH process, a positive value of $a_{11}$ associated with a positive (negative) shock to the price level $e_{t-1}$ raises (reduces) the expected price variance $h_{t}$.

The final specification estimated in the article is the GARCH-in-mean (GARCH-M) model to check whether in addition to being rational, speculators are also risk-averse so that the expected variance has explanatory power. The GARCH-M provides an explicit link between both the conditional mean and price variance, and is derived from a simple extension of (6) which becomes

$$
P_{t}=\alpha+\beta t+\sum_{i=1}^{p} \rho_{i-1} P_{t-i}+\theta_{1} \sqrt{h_{t}}+\theta_{2}\left(P_{t-1} \sqrt{h_{t}}\right)+e_{t}
$$

Theoretically, if the assumption of risk-averse storers were to hold, $\theta_{1}$ should be positive given that the more volatile the expected price the lower the amount stored which induces not only a

\footnotetext{
${ }^{8}$ See the appendix of the source paper for details on the decomposition of $e_{t}$ in both the demand and supply components.

${ }^{9}$ In the absence of the storage mechanism, the expected variance is constant since it is a function only of the variance of external shocks which are assumed to be constant.
} 
higher price level next period but also weaker serial correlation $\left(\theta_{2}<0\right)$.

Interestingly, using annual prices for twenty storable and non-storable commodities from the Commodity Research Bureau (CRB) and the US Department of Agriculture (USDA), Beck finds a significant $\mathrm{ARCH}(1)$ process only in the behavior of the former category as predicted by the theory. However, testing for the explanatory power of the conditional variance of prices shows no clear distinction between the two types of commodities. The significant skewness in the behavior of the prices of some storable and non-storable commodities suggests that this asymmetry does not stem entirely from the zero lower bound constraint on stocks, and that other forces might be at play. Finally, consistent with the assumption of risk-neutral storers in the standard storage model, the estimation results from (9) indicate that the forecasting power of the expected variance of prices is not significant.

Indirectly, another proof that would seem to support the speculative theory of storage is provided by Roberts and Schlenker (2013) whose instrumental variable approach relies crucially on the validity of speculative storage theory. Their paper is innovative in that in line with their earlier work (Roberts and Schlenker, 2009), they account for the high degree of substitutability between production and consumption for the major crops by working with the price index based on the caloric aggregate of grains and soybeans. They show that this indicator better reflects the state of the world food market than use of any of the four component crops on their own. They also develop a novel identification strategy in which past yield shocks have an effect on the levels of inventories carried over, and in turn, on futures prices through the storage mechanism. Therefore, assuming non-correlation of weather and demand shocks, past production disturbances can be used to separately identify supply and demand elasticities. Other successful attempts to use storage theory to eliminate possible confounding factors and explain a typical price feature or isolate a clear causality channel can be found in Coleman (2009) and Steinwender (2018) who respectively work with the prices of corn and cotton.

Insightful futures prices From a different perspective, the finance literature has examined some of the expected effects of storage on the behavior of futures prices and forward curves. $\mathrm{Ng}$ and Pirrong (1994) exploits the long-term equilibrium relationship between the forward and spot prices to derive a variety of testable consequences of storage theory which are detailed and documented in Williams and Wright (1991). They are all related to the correlations between spot price volatility and inventories, and spreads between forward and spot prices. Recalling that if agents are risk-neutral the forward price is equal to the expected spot price, from the arbitrage condition (1) they compute the spread net of the storage and interest costs such that

$$
Z_{t}=\beta F_{t, T}-P_{t}-k
$$

where $F_{t, T}$ is the forward (or futures) price at time $t$ expiring at time $T>t .{ }^{10}$ Storage theory states that the lag spread $Z_{t-1}$ has explanatory power. The intuition is that if supply and demand conditions are the prominent drivers of commodity price dynamics, a substantial degree of variation might be explained by the past values of the adjusted spread $Z_{t-1}$ given that the

\footnotetext{
${ }^{10}$ Under risk-neutrality and constant interest rates assumptions, the distinction between futures and forward prices is irrelevant (Williams and Wright, 1991). Therefore, I use these two terms interchangeably in the rest of the article.
} 
wider the adjusted spread in absolute value, the lower will be the level of inventories carried over and the more susceptible the markets will be to shocks. ${ }^{11}$ It is the lagged spread value which summarizes the information at time $t-1$ (e.g., prior to the shock), and which in turn matters for forecasting the variations in spot and futures prices. Turning to the specification of the estimated model, the authors express the conditional means of the logarithm of spot and futures prices as an error-correction model with time-varying means, variances and covariances in the form

$$
\Delta \ln S_{t}=\alpha_{S}+\sum_{i=1}^{5} \beta_{i, S} \Delta \ln S_{t-i}+\sum_{i=1}^{5} \gamma_{i, F} \Delta \ln F_{t-i}+\mu_{S} Z_{t-1}+\epsilon_{S, t}
$$

and

$$
\Delta \ln F_{t}=\alpha_{S}+\sum_{i=1}^{5} \beta_{i, F} \Delta \ln F_{t-i}+\sum_{i=1}^{5} \gamma_{i, S} \Delta \ln S_{t-i}+\mu_{F} Z_{t-1}+\epsilon_{F, t}
$$

where the commodity is denoted by $i$, and the error terms $\epsilon_{S}$ and $\epsilon_{F}$ are assumed to obey a GARCH $(1,1)$ process augmented by the adjusted term spread (i.e. an augmented bivariate $\operatorname{GARCH}(1,1)$ model). Hence, the conditional covariance $\sigma_{S, F, t}$ and variances $h_{S, t}$ and $h_{F, t}$ of the spot and futures prices can be written as:

$$
\begin{gathered}
h_{S, t}=\omega_{S}+\delta_{1} h_{S, t-1}+\delta_{2} \epsilon_{S, t-1}^{2}+\delta_{3} Z_{t-1}^{2}, \\
h_{F, t}=\omega_{F}+\phi_{1} h_{F, t-1}+\phi_{2} \epsilon_{F, t-1}^{2}+\phi_{3} Z_{t-1}^{2}, \\
\sigma_{S, F, t}=\rho \sqrt{h_{F, t} h_{S, t}}+\theta Z_{t-1}^{2} .
\end{gathered}
$$

Although it is overlooked in previous studies, equation (15) provides an explicit link between the spread and the covariances of spot and forward prices, and is an important innovation in $\mathrm{Ng}$ and Pirrong. According to storage theory, the cointegration relationship between spot and forward prices becomes weaker with the reduction in the amounts stockpiled associated with an increasing lag adjusted spread (i.e., $\theta<0$ ). The link is broken if the commodity is stocked out. At full carry, $Z_{t-1}$ is zero and $\rho \approx 1$ since spot and futures prices are almost perfectly correlated.

Equations (11)-(15) are estimated as a system using daily spot and three-month forward prices for four of the major industrial metals, plus silver, a precious metal which might behave differently because of its safe-haven status which is accompanied by large amounts hoarded, and thus, very small and stable spread. The authors also use the London Metal Exchange Ltd. warehousing fees to proxy for the physical costs of carrying $k$. The reported results are encouraging, and confirm the predictions of the theory in many respects. Not only do both spot and to a lesser extent forward-return volatilities vary significantly with the square of the adjusted spread $\left(Z_{t-1}^{2}\right)$ (i.e., $\delta_{3}>\phi_{3}>0$ ) but also $(i) Z_{t-1}^{2}$ is inversely related to the correlations between spot and forward returns, $(i i)$ the forward price elasticity defined as $e_{t}=\Delta \ln F_{t} / \Delta \ln S_{t}=\sigma_{S, F, t} / h_{S, t}$ falls with inventory drawdowns while approaching 1 at full carry, (iii) together the lagged-squared spreads account for between $50 \%$ to $70 \%$ and $50 \%$ to

\footnotetext{
${ }^{11}$ In the empirical part, the authors prefer the squared spread values to the absolute values specification since they offer a better fit but do not change the qualitative results.
} 
$60 \%$ of innovations in industrial metal spot-and-forward-return variances respectively, and as expected, $(i v)$ in the case of silver prices the parameter estimates are statistically insignificant.

Working with crude oil prices, Routledge et al. (2000) explore the implications of the storage mechanism for the behavior of the term structure of forward prices. In the basic set-up, prices are driven by transitory demand shocks following a Markov process with two states-high and low. After studying and illustrating the many consequences linked to the introduction of storage arbitrage and a lower bound on inventories the authors exploit the data to check in which dimensions such a one factor model offers the best and the worst fits. Particular attention is paid to the slope of the forward curve whether increasing-contango-or decreasing-backwardation-with respect to the contract horizon. Intuitively, low incoming storage has a less depressing effect on futures prices, and so is associated with higher and more volatile spot and near term forward contracts. This happens because a backwardated market is more vulnerable to a positive demand shock causing a price peak and a stockout. The model is calibrated using NYMEX crude oil daily futures prices. First, the authors fix the constant decay and interest rates at low values based on the estimates in Deaton and Laroque (1992), and then they select the values of the other parameters to match the mean and standard deviations of prices with and without conditioning on the shape of the forward curve a month prior. If the model resembles the unconditional volatility, it does not account for the conditional moments. This can be due to a too small and not sufficiently volatile amount of stocks accumulated in backwardation. It turns out that the spot price is driven primarily by the transitory shock process which is unable to generate long-run volatility matching the observed conditional variations. Although not mentioned in the article, another possible reason for the volatility mismatch between real storage levels and those predicted by the theory might be the idiosyncratic nature of the storage options for crude oil. It is difficult to accurately track and estimate the true levels of available inventories among those kept secret, left in the ground, or stored at sea by playing with the shipping speed. To resolve this issue, Routledge et al. add to the model a permanent demand shock which is assumed to be log-normally distributed. The idea is that inventories and transitory shocks shape only the front-end of the forward curves while the permanent component has a long-lasting effect which pins down the substantial volatility of futures observed over the longer horizon. The augmented model provides a much better fit with the data, and especially when forward prices are backwardated. Taken together, the promising empirical results in the finance literature suggest that in the competitive storage model with rational expectations, the forward-looking behavior of agents would appear to be particularly well suited, at least in the short-run, to govern the movement of forward prices. Further empirical studies could benefit from the substantial amount of valuable information stemming from the dynamics of futures prices. In this vein, it is worth mentioning the stream of work on structural vector autoregressive (SVAR) models (Kilian and Lütkepohl, 2017). Papers using the SVAR modeling and linked to storage theory include the contributions of Kilian (2009), Inoue and Kilian (2013), Kilian and Murphy (2014) and Baumeister and Hamilton (2015) in the case of oil, and Carter et al. (2016) and Janzen et al. (2018) for agricultural products.

On the whole, empirical studies based on reduced-form versions of the competitive storage model provide mixed results. However, rejection based on the data of some aspects of the core storage theory does not mean that it is irrelevant for explaining price fluctuations in the spot 
and futures commodity markets. Also, the point about such limited information estimation techniques is that they leave many key parameters unidentified which precludes comparisons between the price series distribution generated by the estimated model and actual prices. One solution is to rely on structural econometric methods which I discuss next.

\subsection{Structural estimation techniques}

Structural estimation approaches push the reconciliation between the theory and observations even further by taking the structural model directly to the data, thereby providing a full characterization of the observed price series. The idea is to use the economic theory to complement the sparse data as suggested by Varian (1989). Those empirical strategies are often less robust than their non-structural counterparts which is the classical trade-off between robustness and full identification of the parameters governing the behavior of prices. More specifically, these strategies are applied at the cost of $(i)$ taking a stand on the functional form of both the demand and storage cost functions, $(i i)$ fixing some of the parameters that cannot be identified when inferences are drawn only on prices, and (iii) solving for the intractable price policy function needed to build the information-theoretic estimators. ${ }^{12}$ An even more serious limitation is that this last numerical resolution has to be done for every set of parameters in the maximization routine which renders the whole estimation procedure computationally very demanding.

The methodological breakthrough All these problems were resolved in the path-breaking papers by Deaton and Laroque $(1995,1996)$ which deal with the price autocorrelation puzzle raised in Deaton and Laroque (1992). Specifically, the authors assume a downward sloping linear demand for consumption $D(P)=(P-a) / b$, a physical storage cost proportional to the quantities in store and captured by the decay rate $\delta,-$ i.e. $k=0$ in equation (1)-a fixed interest rate $r=5 \%$ and an i.i.d. normally distributed supply process $\epsilon$ with mean $\mu$ and variance $\sigma^{2}$. Moreover, given that the estimation relies only on prices, they demonstrate that it is not possible to differentiate the demand and supply parameters. Hence, they assume $\mu=0$ and $\sigma^{2}=1$ so that $\epsilon$ is unit normal. Having laid out the general assumptions, Deaton and Laroque develop a structural estimation strategy based on the pseudo-maximum (log)-likelihood (PML) which falls into the class of information-theoretic estimators. ${ }^{13}$ Below, I set out the main elements.

First, they solve for the price policy function $\mathcal{P}(A ; \theta)$ given the availability level $A$ and the set of structural parameters stacked in $\theta \equiv(r, \delta, a, b)$. As required for the numerical resolution, $\epsilon$ is approximated by a Gaussian quadrature with 10 equiprobable nodes. ${ }^{14}$ Then, still working with the thirteen price series taken from the World Bank (WB) dataset, and recalling the

\footnotetext{
${ }^{12}$ Since there is no closed-form solution for the price policy function, it has to be numerically approximated. Gustafson (1958) pioneered numerical techniques which were developed and became established in the literature by Wright and Williams (1984); Williams and Wright (1991) before being thoroughly reviewed and even completed in Gouel (2013). Ultimately, all resolution methods require approximation of the distribution of the stochastic process to obtain a problem of a finite dimension.

${ }^{13}$ Contrary to the full information maximum likelihood method, the PML abstracts from the third to higher moments in the price distribution, while maintaining consistency (Gourieroux et al., 1984). Put differently, unlike supply shocks, price observations are not assumed to be normally distributed.

${ }^{14}$ In their papers, Deaton and Laroque propose a fixed-point algorithm which provided that the supply is assumed to be inelastic is not only very robust but also very fast. This explains why it quickly became the standard method applied in most subsequent articles dealing with structural estimations of the storage model.
} 
state-dependency between prices induced by the storage channel, the authors compute the first two conditional moments of $P^{\text {obs }}$, denoted respectively $\mathrm{M}\left(P_{t}^{\text {obs }} ; \theta\right)$ and $\mathrm{S}\left(P_{t}^{\text {obs }} ; \theta\right)$, entering the PML function and written as:

$$
\begin{aligned}
\mathrm{M}\left(P_{t}^{\mathrm{obs}} ; \theta\right) & =\mathrm{E}\left(P_{t+1}^{\mathrm{obs}} \mid P_{t}^{\mathrm{obs}} ; \theta\right) \\
& =\sum_{n=1}^{N=10}\left\{\epsilon_{t+1}^{n}+(1-\delta)\left[\mathcal{P}^{-1}\left(P_{t}^{\mathrm{obs}} ; \theta\right)-D^{-1}\left(\mathcal{P}\left(A_{t} ; \theta\right)\right)\right]\right\} \operatorname{Pr}\left(\epsilon_{t+1}^{n}\right),
\end{aligned}
$$

and

$$
\begin{aligned}
\mathrm{S}\left(P_{t}^{\mathrm{obs}} ; \theta\right) & =\mathrm{V}\left(P_{t+1}^{\mathrm{obs}} \mid P_{t}^{\mathrm{obs}} ; \theta\right) \\
& =\sum_{n=1}^{N=10}\left\{\epsilon_{t+1}^{n}+(1-\delta)\left[\mathcal{P}^{-1}\left(P_{t}^{\mathrm{obs}} ; \theta\right)-D^{-1}\left(\mathcal{P}\left(A_{t} ; \theta\right)\right)\right]\right\}^{2} \operatorname{Pr}\left(\epsilon_{t+1}^{n}\right)-\mathrm{M}\left(P_{t}^{\mathrm{obs}}\right)^{2}
\end{aligned}
$$

where $\epsilon^{n}$ and $\operatorname{Pr}\left(\epsilon^{n}\right)=0.1$ are respectively the nodes and their associated probabilities of the supply process discretization. $\mathrm{M}\left(P_{t}^{\text {obs }} ; \theta\right)$ and $\mathrm{S}\left(P_{t}^{\text {obs }} ; \theta\right)$ finally can be combined to form the $\operatorname{PML}\left(\theta ; P_{1: T}^{\text {obs }}\right)$ estimator:

$$
\begin{aligned}
\operatorname{PML}\left(\theta ; P_{1: T}^{\mathrm{obs}}\right)= & -\frac{1}{2}\left(\left((T-1) \ln 2 \pi-\sum_{t=1}^{T-1} \ln \mathrm{S}\left(P_{t}^{\mathrm{obs}} ; \theta\right)\right)\right)- \\
& \frac{1}{2}\left(\left(\sum_{t=1}^{T-1} \frac{\left(P_{t+1}^{\mathrm{obs}}-\mathrm{M}\left(P_{t}^{\mathrm{obs}} ; \theta\right)\right)^{2}}{\mathrm{~S}\left(P_{t}^{\mathrm{obs}} ; \theta\right)}\right)\right) .
\end{aligned}
$$

At the heart of the estimation procedure is the ability to recover the observed availability $A^{\text {obs }}$ directly from $P^{\text {obs }}$ by inverting the monotonously decreasing price policy function $\mathcal{P}$ so that $A^{\text {obs }}=\mathcal{P}^{-1}\left(P_{t}^{\text {obs }}\right)$. This is imposed to solve for $\mathcal{P}$ for each change in the value of $\theta$. Hence, to identify the parameters included in $\theta$, the PML optimization routine needs to nest an inner numerical algorithm for the model resolution which as mentioned above, makes the whole procedure computationally cumbersome.

The estimation results were as disappointing as the approach was innovative and inspiring; the model again fails to induce more than half of the autocorrelation levels measured in the true data, regardless of the commodity under study. Put differently, the transmission of shocks through the inventory channel accounts for only a small part of the commodity price variations in a market driven by i.i.d. fluctuations in production. Perhaps even more discouraging was the finding that a basic linear autoregressive model (AR(1)) offers a better fit. Going further and concomitant with Chambers and Bailey (1996), the authors relaxed the assumption of an i.i.d. unit normal harvest shock and assumed that supply disturbances followed only an AR(1) process, denoted $z_{t}$, and which introduced an additional source of persistence in the model dynamics. ${ }^{15}$ Looking beyond the theoretical plausibility of such a hypothesis, for instance in the

\footnotetext{
${ }^{15}$ The $\operatorname{AR}(1)$ process is written as $z_{t+1}=\rho z_{t}+\epsilon_{t+1}$ with $\rho$ the autocorrelation coefficient and $\epsilon$ a white noise with zero mean and unit variance. It is approximated by a Markov chain limited to the 10 node values of $\epsilon$ and in
} 
case of annual crops such as grains, in spite of this richer modeling the findings are discouraging as acknowledged by the authors in saying: "we find these results almost as disappointing as those for the storage model with i.i.d. harvests". Indeed, the higher levels of serial correlations obtained result almost entirely from the estimated value of $\rho$. All in all, the model cannot match the high degrees of serial correlation observed in the actual price data regardless of the assumed degree of persistence in the distribution of the supply innovations.

However, Deaton and Laroque's methodology definitely paved the way to future structural estimation of the competitive storage model. Moreover, as discussed above, in the same way as the lack of power of a statistical test can lead to a spurious rejection of the hypothesis of significant storage effects, the apparent autocorrelation failure does not necessarily mean rejection of the storage theory per se. As noted in Cafiero and Wright (2006), it is related rather to the wrongness of parts of the assumptions needed including the functional form of the storage cost or linear demand functions, the absence of both demand shocks and supply reaction to the related production costs and capital dynamics, the nature of the innovations (e.g. size, distribution, independence), and the fixed interest rate value.

Additionally, this sensitivity to the model hypotheses is confirmed by the more optimistic results obtained from another literature stream initiated by Kaldor (1939) and Working (1949) which rests on the convenience yield hypothesis. This assumption is related to the flow of services accruing to the stockholders, and is justified on the grounds of timely deliveries and avoided costs either through disruption to the manufacturing process, or the trading advantage that the commodity owner enjoys in the event of a price spike. ${ }^{16}$ The convenience yield prevents the occurrence of stockout situations which allows a much better fit of the measured autocorrelation (Miranda and Rui, 1999).

However, persisting with the assumption of the non-negativity constraint on inventories, Cafiero and Wright (2006) point to several theoretical and technical improvements to deal with this empirical failure.

Technical achievements Building upon Deaton and Laroque (1996)'s PML, Cafiero et al. (2011) demonstrate that a model with constant marginal storage cost which is solved with higher accuracy fits the behavior of prices better. Considering carrying costs proportional to the amount stored is problematic since it makes stockholding increasingly more expensive with price. This in turn, decreases the incentive to store which is the single source of time dependency of prices in the model. As a result, Cafiero et al. suggest setting the decay rate of inventories $\delta$ to zero, and estimating a constant marginal storage cost $k$. Also crucial is the precision in the numerical approximation of the price policy function given that a substantial part of the inference relies on accurate location of the kink in the price function at the cut-off value denoted $P^{*}$ above which there are no carryovers. Specifically, recalling that the lower $P^{*}$ the more time in the stockout region and the less serial correlation generated by the model, an underestimation of $P^{*}$ entails a

which the associated transition probabilities are calculated so as to match a predetermined $\rho$. Note also that $z_{t}$ appears as a second state variable in the system which makes the estimation trickier as shown in the associated technical paper (Deaton and Laroque, 1995).

${ }^{16}$ Technically, it can be obtained by modeling storage cost as a marginal log-linear function of the amount stored which becomes infinitely negative as inventory levels tend to zero. $P^{*}$ being infinite the constraint is never binding. Another appeal of this approach is that it allows computation of the Maximum Likelihood estimator. 
reduction in the model's ability to induce high levels of autocorrelation in prices. ${ }^{17}$

Michaelides and $\mathrm{Ng}$ (2000) compare the asymptotic properties of the PML with three simulated estimators: simulated methods of moments (Darrell Duffie, 1993), efficient method of moments (Gallant and Tauchen, 1996), and the indirect inference estimator (Gourieroux et al., 1993). Developed in the 1990's, these computationally intensive estimation procedures were aimed at providing alternative estimators able to reveal the structural parameters of models with no closed-form solutions. Through a series of Monte-Carlo experiments, Michaelides and $\mathrm{Ng}$ show that what the PML gains in efficiency and precision in the sense of a smaller root mean-squared error, it loses through the larger estimation biases which are not decreasing with the sample size. More precisely, it leads to overstatement of the decay rate $\delta$ and overestimation of demand elasticity which combined translate into too frequent periods of zero stocks which reduces the ability of the model to generate autocorrelation in prices. For instance, with an annual deterioration rate of $16.9 \%$, the estimation results for cotton imply that inventories are held for only half of the time between 1900-1987 which is the sample interval, which clearly is not plausible.

With this in mind, Cafiero et al. (2015) proposed a full information maximum likelihood estimator (FIMLE) with better small sample performance properties, and which when applied to the price of sugar, delivers a much more optimistic view of the empirical consistency of the storage model. Although these results were more promising, trying to match the whole of the autocorrelation observed in the prices comes at the cost of overstating the role of storage in the formation of prices. Hence, as Cafiero and Wright (2006) note and Gouel and Legrand (2017b) explain, it might be that part of the serial correlation in commodity prices cannot be accounted for by the standard storage model.

The resolution of these numerical and specification issues, by yielding much more positive conclusions regarding the model's ability to generate sufficient persistence in prices, rekindled interest in the competitive storage model and the underlying theory. Having said this, as Gouel and Legrand (2017b) show, the higher autocorrelation levels are obtainable solely with very low values of demand elasticity and storage costs $k$. As a result, over the whole data sample spanning 1900 to 1987 the estimated number of stockouts is very small or zero. This is problematic given that the main appeal of the storage model is precisely its faculty to deliver two price regimes depending on whether stocks are carried over. Together these results suggest exploration of the data rather than just the model specification as suggested by Cafiero and Wright (2006). The underlying logic is that part of the serial correlation in prices might be unrelated to either storage theory and the associated transfer of inventories, or to any kind of economic mechanism. It may be an artifact of how the series are constructed and deflated. Thus, trying to fit this aspect of the price data is likely to come at the expense of the reliability of the whole estimation procedure. Also, in an empirical test of the consistency of a given theory, data issues are at least as important as those issues related to the actual model specification.

Empirical refinements Guerra et al. (2015) address the potential problem of spurious time dependencies due to the construction of yearly price series. Indeed, the data used thus far are

\footnotetext{
${ }^{17}$ According to the authors a number of points on the approximation grid in the range 500 to 1000 appears to be sufficient compared to the 20 to 45 points depending on the commodities used in Deaton and Laroque (1996).
} 
calendar averages of monthly prices, and thus mix spot prices from two consecutive production cycles. Working with the MLE proposed by Cafiero et al. (2015) in the context of the price of corn over the period 1949-2012, the authors test eight averaging methods to construct annual price indexes, and find sizeable effects across samples. For instance, one of the key parameter estimates, the elasticity of demand for consumption, can vary by more than a factor of two if the annual index consists of the daily average for the month of November rather than the calendar year. Overall, they obtain the best fit when using an annual value built as the daily average over the single month of December as in Roberts and Schlenker (2013).

The second major concern is quite standard in econometrics and concerns the non-stationarity of the data. Specifically, commodity prices are likely to exhibit long-run trends. Figure 1 illustrates this in the case of maize. There is a visible long-run, downward sloping trend. Also,

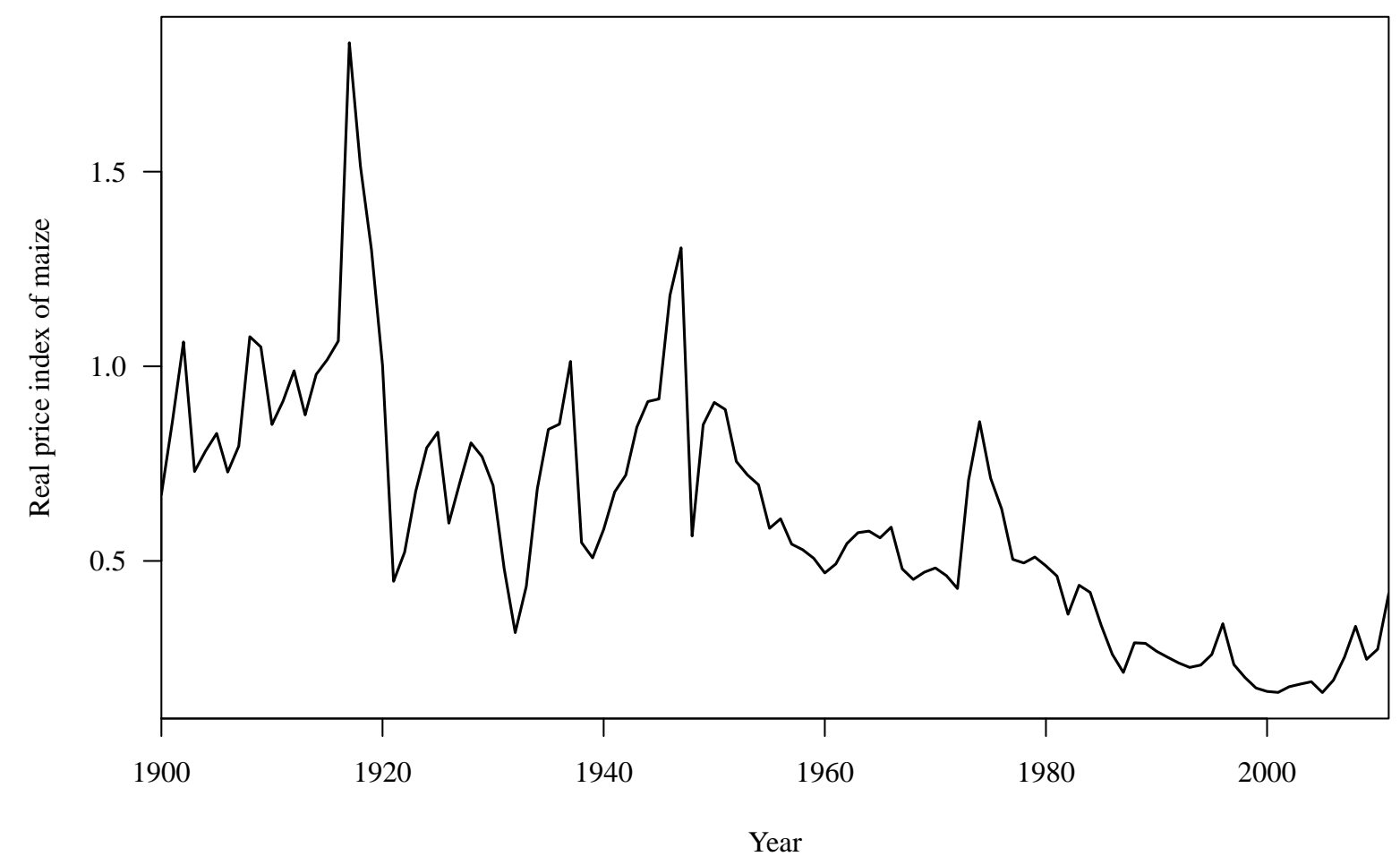

Figure 1: Annual real annual price index of maize (1900-2011). Source: World Bank Development Prospects Groups.

there is a difference in magnitude between the very wild short-run variations in prices with respect to the slow decreasing trend. In other words, the volatility tends to dominate the long-run trend along with all the lower frequency movements. The key challenge when disentangling these components whether to test for data stationarity, or to infer parameter values. To extend this preliminary crude visual inspection with formal unit root tests, I adopt the strategy in Ghoshray (2011) and conduct the Lee and Strazicich (2003) test which allows for shifts in trend parameters under both the null and the alternative hypotheses, so that rejection of the null necessarily implies trend stationarity. The results are reported in table 3.

Table 3 shows that at the $10 \%$ significance level or below, 9 out of the 13 commodities studied are trend stationary with one or two structural breaks. These findings differ slightly 
Table 3: Lee-Strazicich unit root test with structural breaks in intercept and slope

\begin{tabular}{lcccl}
\hline Commodity & $\mathrm{k}$ & TB1 & TB2 & t-stat \\
\hline Banana & 1 & 1941 & 1996 & $-6.994^{* * *}$ \\
Cocoa & 2 & 1946 & - & -3.055 \\
Coffee & 2 & 1945 & 1987 & -4.353 \\
Copper & 1 & 1917 & - & $-4.578^{* *}$ \\
Cotton & 1 & 1928 & 1950 & $-7.228^{* * *}$ \\
Jute & 3 & 1927 & 1947 & $-5.648^{* *}$ \\
Maize & 1 & 1916 & 1936 & $-5.497^{*}$ \\
Palm oil & 1 & 1983 & - & $-5.018^{* *}$ \\
Rice & 7 & 1933 & 1982 & $-5.588^{*}$ \\
Sugar & 5 & 1919 & 1974 & $-5.412^{*}$ \\
Tea & 2 & 1934 & 1964 & -5.114 \\
Tin & 11 & 1972 & 1988 & -5.093 \\
Wheat & 3 & 1925 & - & $-5.394^{* * *}$ \\
\hline
\end{tabular}

Note: ${ }^{* * *},{ }^{* *}$, and ${ }^{*}$ denote significance at the $1 \%, 5 \%$, and $10 \%$ levels respectively. $\mathrm{k}$ is the lag length used in Ghoshray (2011, Table 3) when available, or the general-to-specific method suggested in Lee and Strazicich (2003). TB1 and TB2 are the first and second break dates.

from those reported by Ghoshray (2011) who ran the test on the same World Bank dataset but deflated by the Manufactures Unit Value (MUV) index and on a shorter sample (i.e. 1900-2003), both of which are likely to affect the results of the unit root tests. Specifically, the null of a unit root with breaks is rejected for jute and sugar but not for tin and tea while bananas and maize display a trend stationary process with two rather than one breaks. Furthermore, in line with the relative measures of a trend prevalence documented in Ghoshray (2011, Table 6), the four commodities (coffee, cocoa, tea, and tin) for which the price series are not trend stationary with breaks, are also those exhibiting trendless behavior for at least $50 \%$ of the sample. For the remaining nine commodities, Ghoshray also finds evidence of the presence of trend segments. Finally, notice that results vary across commodities $(i)$ confirming that there is a host of possible reasons for the presence of the trends, and (ii) strengthening the relevance of working on an individual commodity basis rather than an index, and especially since the list of commodities includes both renewable and non-renewable commodities.

In light of these results, although most commodities are found to be trend stationary, this is by segments divided by infrequent shifts. Building on this, Gouel and Legrand (2017b) proposed joint estimation of the structural and trend parameters. Canova (2014) introduced the hybrid trend and cycle decomposition method for macro-series which is attractive because it removes the influence of a trend without restricting the model specification, while allowing different trend specifications to be tested and compared in order to select the set-up which best fits the data. ${ }^{18}$ Overall, accounting for a trend in the estimation procedure has a non-negligible impact on the estimated demand elasticity and storage cost values which are both higher, and closer to those found in other studies, notably Roberts and Schlenker (2013). This implies the occurrence of rare stockout episodes when prices spike, providing further support for the empirical relevance

\footnotetext{
${ }^{18}$ From a modeling perspective, a more desirable choice would be to incorporate realistic trends directly into the structure of the storage model.
} 
of the competitive storage model and mitigating the initially discouraging conclusions in Deaton and Laroque (1996).

However, although the speculative activity of stockholders generates a price dynamics consistent with the main stylized facts observed in the data, further extensions of the simple annual theoretical model are needed to provide a more comprehensive picture of the behavior of commodity prices. A first step in that direction is Ng and Ruge-Murcia (2000). In an effort to account for the lack of persistence generated in prices, they extend the canonical version of the storage model to include more realistic features of the supply process and functioning of futures markets likely to encourage agents to carry more inventories, which induces higher levels of serial correlation generated by the model. The authors alternatively introduce gestation lags with heteroskedastic supply shocks, multiperiod forward contracts and a convenience return to inventory holding, and using simulated price series, they assess the increased persistence that each of these modifications enables. The authors find that although all three extensions lead to more autocorrelated prices, even in the most successful version where gestation lags with heteroskedastic supply shocks are incorporated within the production dynamics, a substantial part of the observed persistence remains unaccounted for. Having said this, the higher degrees of serial correlations in prices is not the only puzzling phenomenon which lacks a coherent theory. Chief among these is excessive co-movements.

\subsection{The excess co-movements puzzle}

The expression excess co-movements was coined by Pindyck and Rotemberg (1990) who show that commodity prices exhibit excessive covariations even after controlling for the main classical common macroeconomic drivers of the dynamics in the global commodity market.

The key to their approach is that they consider not only the direct effects of these macroeconomic factors but also the indirect effects on the expected supply and demand conditions. Storage theory is at the heart of their empirical strategy. Specifically, rearranging equation (1) for a commodity $i$, they express the interest rate as a function of the expected and spot prices along with the carrying cost:

$$
r_{t}=\frac{\left[\mathrm{E}_{t} P_{i, t+1}-C_{i, t}-P_{i, t}\right]}{P_{i, t}}
$$

where $C_{i, t}$ is the period $t$ cost of carrying the commodity including the constant physical storage cost $k$ less the capitalized flow of its marginal convenience yield which is a function of the level of inventories $S$ as well as current and past values of the macroeconomic variables which directly affect the market conditions, and thus, the price. After some algebra based on equation (19) they relate the change in the commodity price to the set of current and past values of the macroeconomic variables and possibly past price variations through the following two regression equations: ${ }^{19}$

\footnotetext{
${ }^{19}$ Details of the computation are provided in the appendix.
} 


$$
\begin{gathered}
\Delta p_{i, t}=\sum_{k=0}^{K} \alpha_{i, k} \Delta x_{t-k}+\sum_{k=0}^{K} \beta_{i, k} \Delta z_{t-k}+\epsilon_{i, t} \\
\Delta p_{i, t}=\sum_{k=0}^{K} \alpha_{i, k} \Delta x_{t-k}+\sum_{k=0}^{K} \beta_{i, k} \Delta z_{t-k}+\rho_{i} \Delta p_{i, t-1}+\epsilon_{i, t}
\end{gathered}
$$

where the vector $x$ includes the current and past values (up to the lag $K$ ) of the index of industrial production, the CPI, the nominal interest rate on the 3-month Treasury bills, an equally-weighted index of the dollar value of the German mark, the Japanese yen, and the British pound, and $z$ embeds the money supply and the $\mathrm{S} \& \mathrm{P}$ common stock index, while $\epsilon$ is the error term which is assumed to be normally distributed and serially uncorrelated in (20) but not in (21). Finally, under the null of absence of excess co-movements across commodities, $\mathrm{E}\left(\epsilon_{i, t} \epsilon_{j, t}\right)=0 \forall i \neq j$, i.e. after controlling for past, current and expected effects of the primary common macroeconomic determinants, no systematic or predictable correlations should persist in the residuals. Put simply, under the null any correlations in the error structure are assumed to be insignificant and purely fortuitous.

The authors estimate equations (20) and (21) using Ordinary Least Squares (OLS) working with the 1960-1985 monthly, quarterly and annual series of the US cash price of seven commoditiescrude oil, gold, lumber, copper, cocoa, cotton, and wheat-and test for the excess co-movements hypothesis using the likelihood ratio statistic. For all commodities, and at all frequencies, the null of no excessive co-movements across commodities is rejected. In an attempt to assess the magnitude of the marginal explanatory power of this excess of co-movements they consider the $R^{2}$ values of the OLS regressions and find that a large share-i.e. up to one half in the case of cotton-of the variance in commodity price changes is explained by these excessive contemporaneous variations.

Before a definitive refutation of the canonical speculative storage model, Pindyck and Rotemberg deem it appropriate to in some way qualify the extent of their findings on the grounds of three weaknesses. The first is purely statistical and rests on the normality assumption of the regression residuals, likely to be violated by the asymmetry and fat tails exhibited in the commodity price fluctuations and documented in table 1 . This threatens the validity of the procedure, and ultimately could lead to spurious rejection of the null hypothesis. The second weakness is related to one of the assumptions made by the authors that none of these commodities is an important input for the production of some other commodity which excludes the possibility of cointegration relationships among them. Admittedly, given the macroeconomic importance of the oil price which for instance represents a substantial share of agricultural production costs, whether directly (fuel) or indirectly (chemical inputs such as fertilizers), it is hard to deny its influence on the other primary products, and especially today in view of the growing importance of biofuels in the global energy mix. ${ }^{20}$ Nevertheless, among the set of commodities included in the analysis, crude oil price has the highest macroeconomic status, and it is dubious whether, by itself, it was able to account for the lion's share of the significant excessive co-movements measured in the data. The final caveat is common in econometrics;

\footnotetext{
${ }^{20}$ See the textbook by de Gorter et al. (2015) for more on this crucial issue.
} 
since correlation is not causation, it is impossible to rule out the possibility that one or several omitted variables ultimately governs the observed covariances among commodity prices. However, the various factors embedded in the $x$ and $z$ vectors, covering a fairly broad spectrum of the macroeconomic environment, added to the many associated sensitivity analyses confirming the robustness of the core results make the excessive co-movements in commodity prices worthy of further investigation.

In summary, none of the above three shortcomings even when combined would seem enough to relegate such a puzzling phenomenon to a spurious finding or a simple artifact of the data not worthy of being taken seriously, and especially since commodities are not the only class of assets whose prices tend to exhibit excessive co-movements as suggested in Pindyck and Rotemberg (1993) in the case of stocks returns, and more broadly, by the phenomenon of contagion in financial markets described and analyzed in detail in Kaminsky et al. (2003). Moreover, in line with the no less enigmatic autocorrelation discussed above, acknowledging the presence of excessive co-movements across commodity prices does not mean discarding completely the microfoundations of the speculative storage model and the associated rational expectations hypothesis. For instance, Veldkamp (2006) shows that if the acquisition of information is costly, excessive correlations across the earnings of unrelated stocks may well be a rational outcome.

In any case, attempting to solve the autocorrelation and excess co-movement puzzles clearly calls for an extension to the storage model to include some market frictions, improve the model's fit, and hence, widen the scope of structural explanations of commodity price behavior. In this endeavor, some of the most promising strategies are studied and discussed in the next section.

\section{Improving the explanatory power of the storage model}

\subsection{Demand side developments}

A promising direction to enriching the dynamics generated by the storage model is the proposal in Ng and Ruge-Murcia (2000) to introduce more realistic market features, and particularly on the demand side.

Persistent demand shifts This first strategy builds upon the findings in Dvir and Rogoff (2014) who extend the canonical storage model to study the long-run relationships between income growth dynamics and the degree of supply flexibility with inventories and oil price behavior. More specifically, their model embeds both elastic and inelastic supply regimes along with persistent demand shocks. The model then is stationarized by scaling all the quantity variables by aggregate income, measured by the OECD+6 GDP data, and assumed to be the major driver of the growth in consumption. By applying the usual Johansen tests to this set-up, the authors highlight the significant cointegrating links between the prices and market fundamentals of supply, demand, and inventories predicted by the canonical storage model, and consistent with the real data. Perhaps even more importantly, they demonstrate that the correlation between prices and inventories can run in both directions depending on whether supply is sufficiently flexible or not to keep pace with the rising demand trend. Under the inelastic supply regime, price and inventories tend to move in the same direction. 
Regarding the global grains market, the biofuels policies implemented in the EU and the US starting in 2007 caused major disruption. Wright (2014) provides an in depth analysis, in a theoretical setting, of the expected consequences of the addition of a multi-year demand pressure brought by the US ethanol mandates introduced by the 2005 Energy Policy Act. According to Wright, the behavior of grain prices since the early 2000's can be explained by the increased competition between demand for food consumption and demand for energy use. Hence, the simultaneous increases in supply, stocks, and prices which puzzled many contemporary observers is consistent with an anticipated permanent shift in demand for grains following the successive announcements of future biofuels requirements. Overall, although their roles are not understood fully, such demand drivers are powerful, fundamental, and long-lasting forces able at times to reverse the sign of price and inventory co-movements. As a result, they should be incorporated more effectively in the model.

Exchange rate effects Another way to increase the explanatory power of the commodity storage model is to account for the autocorrelated and volatile broader macroeconomic fluctuations embedded in the exchange rate variable. There is a large body of empirical work on the substantial influence that exchange rates can have on the behavior of global commodity prices, and especially since the change from fixed to free-floating exchange rate regimes after the break-down of the Bretton Woods monetary system. For instance, relying on the concept of "commodity currency" exchange rates, ${ }^{21}$ Chen et al. (2010) shed light on a significant causal relationship both in-sample and out-of-sample, running from the exchange rates to the world commodity prices. Granted this apparent exogeneity of exchange rates with respect to commodity prices, there is a case for considering that all the factors affecting the exchange rate are determined outside the commodity market model so that it can enter the model with a reduced-form specification such as a basic AR(1) as in Dvir and Rogoff (2014). In other words, it assumes that the exchange rate is simply an external force aggregating information on the macroeconomic environment and shifting the equilibrium price implied by the model similar in some sense to a persistent demand shock.

The logic resembles that in Deaton and Laroque (1996) and Chambers and Bailey (1996) which consider the introduction of autocorrelated supply shocks to increase the induced persistence in prices but in this case on the demand side. Also, this type of autocorrelated demand shock has a more universal and convincing economic justification. If the findings in Gouel and Legrand (2017b) are used as a guide, the main advantage of such an "ad-hoc" statistical approach is that it helps to improve the fit of the storage model, and potentially leads to less distorted estimated values of the structural parameters while not being too computationally demanding to implement. Indeed, at the cost of very few realistic assumptions, the storage and trade model described in Williams and Wright (1991, Ch. 9) collapses into its standard version for the case of a single country. ${ }^{22}$ As a result, only one exogenous state variable, the exchange rate, is added to the system.

Nevertheless, to further extend and deepen our understanding of the structural mechanisms

\footnotetext{
${ }^{21}$ The concept refers to the free-floating currencies of countries such as Australia, Canada, Chile, New-Zealand, and South-Africa among others whose export revenues depend heavily on commodity exports.

${ }^{22}$ These assumptions ensure a single trade direction in a perfectly-risk sharing situation.
} 
at stake and the directions of the causality, there is a need for a richer storage model which incorporates macroeconomic forces within the core system of equations. In this context, the interest rate might be an useful entry point.

\subsection{The interest rate multiple channels}

So far, all the empirical studies consider the competitive storage model as a single non-linear Euler equation in which the interest rate enters as a simple discount factor assumed to be exogenous and fixed. The hypothesis of it being fixed, which causes the modeling to abstract from the global economic environment, could be another misspecification of the model which is hampering its empirical performance. Dealing with the macroeconomic forces driving the dynamics of commodity prices requires consideration of the general equilibrium effects. Put differently, the commodity market cannot be isolated from other markets such as the forward, money, and stock markets. To study the relationships across these different markets, particular attention needs to be paid to the interest rate. According to Frankel (2014), there are four main channels through which, say, a higher interest rate might weigh on commodity prices:

1. selling of inventories in response to the more costly storage activity;

2. an incentive to increase current production following the logic of the Hotelling principle;

3. a change in the flow of portfolio investments from basic products to Treasury bills;

4. appreciation of the domestic currency leading to a decrease in the dollar denominated commodities on the world market.

Apart from the rather intuitive and direct storage cost channel which was investigated in the previous section, I now discuss and assess the theoretical and empirical relevance of some of the economic mechanisms underlying the indirect effects of the interest rate embodied by the other three channels. The ultimate aim is to improve the model's explanatory power while keeping storage theory center stage.

The latent Hotelling rule On the supply front, assuming that so far only the basic inelastic version of the storage model has been brought to the data, Hotelling's statement that the marginal value of an exhaustible resource should grow at the rate of interest is an appealing extension to the model albeit meaningful only for nonrenewable resources. The point is that thus far, it has been strongly rejected by the observed data (Krautkraemer, 1998). One reason for this is that a higher interest rate is associated also to an increase in the capital cost thereby reducing the rate of extraction and so supply which in turn causes the price to rise. In the end, it is unclear whether an increase in the interest rate eventually leads to an increased or decreased commodity price. In fact, everything depends upon the "in situ" value-i.e. the difference between the price and the marginal extraction cost-of the resource which itself is inversely related to the amount of underground reserves. This is why a more fruitful extension might be to incorporate in the standard storage framework the effects of the dynamics of investment and capital accumulation known to be particularly costly in capital intensive industries. Nevertheless, as Hamilton (2009) 
speculates, Hotelling's notion of scarcity rent rising at the rate of interest might well become more relevant in future years as resources become depleted.

In the meantime, in light of the many possible explanations for the current empirical failure of Hotelling's principle, I do not go into more detail about why the prices of exhaustible resources tend to deviate from the optimal price path which would occur were the theory to hold. ${ }^{23}$ Also, a more relevant alternative approach might be to build on the body of theoretical developments based on the spatial-temporal structure of physical storage costs which have emerged mostly to rationalize the observed stockholding in a backwardated market, meaning when it is uneconomic to carry inventories (Brennan et al., 1997; Bobenrieth et al., 2004, 2008). As shown below, we can obtain also useful insights from investigating the monetary policy channel.

The overshooting theory A typical illustration of what is meant by "non-trivial" patterns in the behavior of commodity prices is the overshooting concept. The core logic is completely analogous to the one embedded in the famous overshooting model originally proposed by Dornbusch (1976) for the case of exchange rates. It was imported into the field of commodity prices by Frankel and Hardouvelis (1985) and Frankel (1986) as a way to feature the interdependence between the financial, money and commodity markets to study the influences of monetary policy on the dynamics of commodity prices.

The key underlying assumption is that in response to a shift in the money supply, commodity prices adjust more rapidly than prices of manufactured goods as demonstrated empirically in Bordo (1980). Remembering the storage arbitrage condition on the expected rate of return of commodities prevailing in the commodity market, the higher interest rate entails a fall in spot prices. However, given the relative stickiness of the other prices, the commodity spot price will overshoot its expected long run equilibrium level where the general price level-consisting of the prices of both primary and manufactured goods-has fully adjusted to the change in money supply. In other words, commodity prices will decline by more than proportionately to the drop in the money supply so as to be sufficiently undervalued to offset the higher real interest rate. Hence, the expected increase in the commodity price covers the rise in the real rate of interest and incentivizes market participants to hold inventories. ${ }^{24}$

Empirical support for this can be found in Browne and Cronin (2010) who seek to test the overshooting theory applied in the context of commodity prices. ${ }^{25}$ Specifically, using US data they apply the maximum likelihood cointegration procedure developed in Johansen (1988) to test for the presence of the long-run dynamic relationships between money, commodity, and consumer prices as posited by the theory. Using the estimated cointegrating relationships, the empirical analysis is finally supplemented by impulse response functions (IRFs) plots of the variables included in the system following a money supply shock. Overall, the adjustments profiles are in line with the theory in that the commodity price index overshoots its long-term

\footnotetext{
${ }^{23}$ Krautkraemer (1998) provides an extensive and thorough overview of these factors which basically are related not only to violations of the efficient market hypotheses going from imperfect competition to incomplete markets and externalities, but also to the discovery of new deposits, technological progress and lack of data availability which render any empirical analyses even more complicated.

${ }^{24}$ See Frankel (1986) for more on the combination of a money demand equation with an expectation-augmented Philips curve and the storage trade-off condition used to quantify the short-run effects subsequent to a monetary shock.

${ }^{25}$ See also Saghaian et al. (2002) and Ching-chong et al. (2005) in the case of agriculture prices.
} 
equilibrium level while the CPI does not. Together, these encouraging results shed light on the empirical relevance of the overshooting theory which interestingly, seems able to provide a theoretical explanation for the excess co-movements puzzle while remaining consistent with the rational expectations foundations of the canonical storage model.

However, the authors mention also that their findings in support of the overshooting theory were obtained using a reduced form model, and thus, cannot be given a structural interpretation. All that can be said is that the predictions derived from the theory are not at odds with the observed data. This calls for full structural estimations of such augmented versions of the storage model once the main computational hurdles related to the greater number of state variables and the so called "curse of dimensionality" are resolved. Another caveat worth noting is the continued unabated volatility despite the previous remarkable period during which both interest rates and inflation were low and stable. Although that might change in future years given the ongoing cycle of monetary policy tightening in major Central Banks (e.g. the Federal Reserve), interest rates cannot be the whole story and other explanations must be found. From this perspective, the burgeoning literature on the integration of financial frictions within stochastic dynamic equilibrium models such as the competitive storage model are worthy of consideration. ${ }^{26}$

\section{Conclusion and Perspectives}

This article presented a variety of theoretical and empirical developments designed to provide structure to the analysis of commodity price volatility in the world market. This literature review helps to isolate some of the crucial features that need to be considered for a sound understanding and prediction of the observed fluctuations in prices which would prove helpful for informing policy debate.

In this respect, the commodity storage model with rational expectations is of particular interest. In its basic version, it consists of a single intertemporal storage Euler equation derived from the optimizing behavior of speculators. Such a very transparent microfoundation is not its unique asset compared to the different way of modeling the behavior of commodity prices embodied in cobweb-type models. Indeed, when it comes to assessing their respective quantitative merits, on the whole the literature is more supportive of a price behavior driven by the market fundamentals affected by exogenous unexpected shocks. From an external consistency standpoint, the superiority of the storage model has been bolstered over the past decade following the many important contributions addressing the autocorrelation puzzle and the other empirical failures of the model highlighted in Cafiero and Wright (2006). However, since short-run volatility can result also from market exuberance, panic, and irrationality, cobweb-type models and the complex price dynamics they can generate are still worthwhile although, ultimately, the price reverts back to the reality dictated by the fundamentals of supply, demand, and inventories.

For this reason the storage model is a good place to start thinking about commodity price volatility for offering a common and basic core structure around which to build and organize policy discussion. In some sense, it could provide the architecture for relevant findings from various fields of finance and economics to eventually be integrated, to improve its explanatory

\footnotetext{
${ }^{26}$ See Cheng and Xiong (2014) for a complete survey of the impacts of financialization on commodity markets, and more particularly through the risk-sharing and information discovery channels.
} 
power, and hopefully, provide some answers to some of the current puzzling phenomena including the persistence and the excess of co-movements in prices.

So far, all the structural estimations of the storage model rest only on price information which greatly limits the number of parameters that can be freely identified. This is the main reason why reasoning from a price change is of little help for deeper empirical analysis with richer storage model specifications. Therefore, it seems crucial that future inferences from the storage model are based on information taken from data on both prices and quantities, especially since the series on quantities have been available for several years. ${ }^{27}$ Using such data would make it possible to draw reliable conclusions about the relative empirical merits of the storage theory. Moreover, confronting the storage model with observed data on both prices and quantities would allow assessment of the dimensions where the model does and does not perform well.

Finally, the conclusions drawn in this paper indicate some directions for a future research agenda that would improve the competitive storage model's explanatory power:

Eclectic storage models in the short-run, in the absence of sound theoretical microfoundations as well as computational advances needed to cope with the current numerical issues, notably those related to the aforementioned curse of dimensionality. The objective would be to improve the overall model fit by embedding reduced form specifications within the structural estimations procedure to capture aspects of the data unrelated to storage theory. One example would be the hybrid estimation approach developed in Canova (2014) to treat long-run trends in macro-series such as commodity prices.

Macroeconomic storage models in the medium-run, to gradually incorporate macroeconomic forces in a structural fashion for instance through the interest rate channel. The goal here, without losing any explanatory power, would be to strengthen the internal consistency of the model by attempting to have as many as possible theoretically grounded relationships among the variables in the framework. In this context, ideally the interdependence between monetary policy and commodity prices should be endogenously derived in an overshooting-type model, instead of intervening as a mere persistent demand shock imitating the broader macroeconomic environment encapsulated in the exchange rate.

Financialized storage models in the long-run, to generate even richer patterns of comovements among commodity and assets prices. The idea is to acknowledge spillovers effects stemming from financial markets flowing into the physical commodity markets, and eventually to achieve a consistent story related to potential speculative bubbles, self-fulfilling prophecies, and other such irrational behaviors. From this perspective, the burgeoning literature in empirical macroeconomics on the integration of financial frictions within stochastic dynamic equilibrium models such as the competitive storage model look promising and worthy of consideration.

\footnotetext{
${ }^{27}$ Gouel and Legrand (2017a) tackle the challenges inherent in structural estimations of the storage model using information on prices and quantities.
} 


\section{References}

Baumeister, C. and Hamilton, J. D. (2015). Structural Interpretation of Vector Autoregressions with Incomplete Identification: Revisiting the Role of Oil Supply and Demand Shocks. Technical report.

Beck, S. (2001). Autoregressive conditional heteroscedasticity in commodity spot prices. Journal of Applied Econometrics, 16(2), 115-132.

Bobenrieth, E., Bobenrieth, J. and Wright, B. (2004). A model of supply of storage. Economic Development and Cultural Change, 52(3), 605-616.

Bobenrieth, E. S., Bobenrieth, J. R. and Wright, B. D. (2008). A foundation for the solution of consumption-saving behavior with a borrowing constraint and unbounded marginal utility. Journal of Economic Dynamics and Control, 32(3), 695 - 708.

Bordo, M. D. (1980). The effects of monetary change on relative commodity prices and the role of long-term contracts. Journal of Political Economy, 88(6), 1088-1109.

Brennan, D., Williams, J. and Wright, B. D. (1997). Convenience yield without the convenience: A spatial-temporal interpretation of storage under backwardation. The Economic Journal, 107(443), 1009-1022.

Browne, F. and Cronin, D. (2010). Commodity prices, money and inflation. Journal of Economics and Business, 62(4), 331-345.

Cafiero, C., Bobenrieth, E. S. A., Bobenrieth, J. R. A. and Wright, B. D. (2011). The empirical relevance of the competitive storage model. Journal of Econometrics, 162(1), 44-54.

Cafiero, C., Bobenrieth, E. S. A., Bobenrieth, J. R. A. and Wright, B. D. (2015). Maximum Likelihood estimation of the standard commodity storage model: Evidence from sugar prices. American Journal of Agricultural Economics, 97(1), 122-136.

Cafiero, C. and Wright, B. D. (2006). Is the storage model a 'closed' empirical issue? The empirical ability of the storage model to explain price dynamics. In A. Sarris and D. Hallam (eds.) Agricultural Commodity Markets and Trade. New Approaches to Analyzing Market Structure and Instability, chapter 4, (pp. 89-114). Northampton: FAO/Edward Elgar.

Canova, F. (2014). Bridging DSGE models and the raw data. Journal of Monetary Economics, $67,1-15$.

Carter, C. A., Rausser, G. C. and Smith, A. (2016). Commodity storage and the market effects of biofuel policies. American Journal of Agricultural Economics.

Chambers, M. J. and Bailey, R. E. (1996). A theory of commodity price fluctuations. Journal of Political Economy, 104(5), 924-957.

Chen, Y.-C., Rogoff, K. S. and Rossi, B. (2010). Can exchange rates forecast commodity prices? The Quarterly Journal of Economics, 125(3), 1145-1194.

Cheng, I.-H. and Xiong, W. (2014). Financialization of commodity markets. Annual Review of Financial Economics, 6(1), 419-441.

Ching-chong, L., Shih-wen, H. and Chih-ping, F. (2005). The overshooting hypothesis of agricultural prices: The role of asset substitutability. Journal of Agricultural and Resource 
Economics, 30(1), 128-150.

Coleman, A. (2009). Storage, slow transport and the law of one price: theory with evidence from nineteenth century u.s. corn markets. The Review of Economics and Statistics, 91(2), 332-350.

Darrell Duffie, K. J. S. (1993). Simulated moments estimation of markov models of asset prices. Econometrica, 61(4), 929-952.

Deaton, A. and Laroque, G. (1992). On the behaviour of commodity prices. Review of Economic Studies, 59(1), 1-23.

Deaton, A. and Laroque, G. (1995). Estimating a nonlinear rational expectations commodity price model with unobservable state variables. Journal of Applied Econometrics, 10, S9-S40.

Deaton, A. and Laroque, G. (1996). Competitive storage and commodity price dynamics. Journal of Political Economy, 104(5), 896-923.

Dornbusch, R. (1976). Expectations and exchange rate dynamics. Journal of Political Economy, 84(6), 1161-76.

Dvir, E. and Rogoff, K. S. (2014). Demand effects and speculation in oil markets: Theory and evidence. Journal of International Money and Finance, 42, 113-128.

Ezekiel, M. (1938). The cobweb theorem. The Quarterly Journal of Economics, 52(2), 255-280.

Frankel, J. A. (1986). Expectations and commodity price dynamics: The overshooting model. American Journal of Agricultural Economics, 68(2), 344-348.

Frankel, J. A. (2014). Effects of speculation and interest rates in a "carry trade" model of commodity prices. Journal of International Money and Finance, 42, 88-112.

Frankel, J. A. and Hardouvelis, G. A. (1985). Commodity prices, money surprises and fed credibilit. Journal of Money, Credit and Banking, 17(4), 425-438.

Gallant, A. and Tauchen, G. (1996). Which moments to match? Econometric Theory, 12(04), $657-681$.

Ghoshray, A. (2011). A reexamination of trends in primary commodity prices. Journal of Development Economics, 95(2), 242-251.

de Gorter, H., Drabik, D. and Just, D. R. (2015). The Economics of Biofuel Policies: Impacts on Price Volatility in Grain and Oilseed Markets. New York: Palgrave macmillan.

Gouel, C. (2012). Agricultural price instability: A survey of competing explanations and remedies. Journal of Economic Surveys, 26(1), 129-156.

Gouel, C. (2013). Comparing numerical methods for solving the competitive storage model. Computational Economics, 41(2), 267-295.

Gouel, C. and Legrand, N. (2017a). Bayesian Estimation of the Storage Model using Information on Quantities. Technical Report 17-776, Toulouse School of Economics (TSE).

Gouel, C. and Legrand, N. (2017b). Estimating the competitive storage model with trending commodity prices. Journal of Applied Econometrics, 32(4), 744-763.

Gourieroux, C., Monfort, A. and Renault, E. (1993). Indirect inference. Journal of Applied Econometrics, 8(S1), S85-S118.

Gourieroux, C., Monfort, A. and Trognon, A. (1984). Pseudo maximum likelihood methods: 
Theory. Econometrica, 52(3), 681-700.

Guerra, E. A., Bobenrieth H., E. S. A., Bobenrieth H., J. R. A. and Cafiero, C. (2015). Empirical commodity storage model: the challenge of matching data and theory. European Review of Agricultural Economics, 42(4), 607-623.

Gustafson, R. L. (1958). Carryover Levels for Grains: A Method for Determining Amounts that are Optimal Under Specified Conditions. Technical Bulletin 1178, US Dept. of Agriculture.

Hamilton, J. D. (2009). Understanding crude oil prices. The Energy Journal, 30(2), 179-206.

Hansen, L. P. and Singleton, K. J. (1982). Generalized instrumental variables estimation of nonlinear rational expectations models. Econometrica, 50(5), 1269-1286.

Inoue, A. and Kilian, L. (2013). Inference on impulse response functions in structural VAR models. Journal of Econometrics, 177(1), 1 - 13.

Janzen, J. P., Smith, A. and Carter, C. A. (2018). Commodity price comovement and financial speculation: The case of cotton. American Journal of Agricultural Economics, 100(1), 264-285.

Johansen, S. (1988). Statistical analysis of cointegration vectors. Journal of Economic Dynamics and Control, 12(2), 231-254.

Kaldor, N. (1939). Speculation and economic stability. The Review of Economic Studies, 7(1), $1-27$.

Kaminsky, G. L., Reinhart, C. M. and Végh, C. A. (2003). The unholy trinity of financial contagion. Journal of Economic Perspectives, 17(4), 51-74.

Kilian, L. (2009). Not all oil price shocks are alike: Disentangling demand and supply shocks in the crude oil market. The American Economic Review, 99(3), 1053-1069.

Kilian, L. and Lütkepohl, H. (2017). Structural Vector Autoregressive Analysis. Cambridge University Press.

Kilian, L. and Murphy, D. P. (2014). The role of inventories and speculative trading in the global market for crude oil. Journal of Applied Econometrics, 29(3), 454-478.

Krautkraemer, J. A. (1998). Nonrenewable resource scarcity. Journal of Economic Literature, 36(4), 2065-2107.

Labys, W. C. (2006). Modeling and forecasting primary commodity prices. Ashgate Publishing, Ltd.

Lee, J. and Strazicich, M. C. (2003). Minimum Lagrange multiplier unit root test with two structural breaks. The Review of Economics and Statistics, 85(4), 1082-1089.

Lowry, M., Glauber, J., Miranda, M. and Helmberger, P. (1987). Pricing and storage of field crops: A quarterly model applied to soybeans. American Journal of Agricultural Economics, 69(4), 740-749.

Michaelides, A. and Ng, S. (2000). Estimating the rational expectations model of speculative storage: A Monte Carlo comparison of three simulation estimators. Journal of Econometrics, 96(2), 231-266.

Miranda, M. J. and Rui, X. (1999). An empirical reassessment of the commodity storage model, mimeo, The Ohio State University. 
$\mathrm{Ng}$, S. (1996). Looking for evidence of speculative stockholding in commodity markets. Journal of Economic Dynamics and Control, 20(1-3), 123-143.

Ng, S. and Ruge-Murcia, F. J. (2000). Explaining the persistence of commodity prices. Computational Economics, 16, 149-171.

Ng, V. K. and Pirrong, S. C. (1994). Fundamentals and volatility: Storage, spreads, and the dynamics of metals prices. The Journal of Business, 67(2), 203-230.

Osborne, T. (2004). Market news in commodity price theory: Application to the Ethiopian grain market. The Review of Economic Studies, 71(1), 133-164.

Pfaffenzeller, S., Newbold, P. and Rayner, A. (2007). A short note on updating the Grilli and Yang commodity price index. World Bank Economic Review, 21(1), 151-163.

Pindyck, R. S. and Rotemberg, J. J. (1990). The excess co-movement of commodity prices. The Economic Journal, 100(403), 1173-1189.

Pindyck, R. S. and Rotemberg, J. J. (1993). The comovement of stock prices. The Quarterly Journal of Economics, 108(4), 1073-1104.

Roberts, M. J. and Schlenker, W. (2009). World supply and demand of food commodity calories. American Journal of Agricultural Economics, 91(5), 1235-1242.

Roberts, M. J. and Schlenker, W. (2013). Identifying supply and demand elasticities of agricultural commodities: Implications for the US ethanol mandate. The American Economic Review, 103(6), 2265-2295.

Routledge, B. R., Seppi, D. J. and Spatt, C. S. (2000). Equilibrium forward curves for commodities. The Journal of Finance, 55(3), 1297-1338.

Saghaian, S. H., Hasan, M. F. and Reed, M. R. (2002). Overshooting of agricultural prices in four asian economies. Journal of Agricultural and Applied Economics, 34(01), 95-109.

Steinwender, C. (2018). Real effects of information frictions: When the states and the kingdom became united. American Economic Review, 108(3), 657-96.

Tong, H. and Lim, K. S. (1980). Threshold autoregression, limit cycles and cyclical data. Journal of the Royal Statistical Society. Series B, 42, 245-292.

Varian, H. R. (1989). What use is economic theory? Technical report.

Veldkamp, L. L. (2006). Information markets and the comovement of asset prices. The Review of Economic Studies, 73(3), 823-845.

Williams, J. C. and Wright, B. D. (1991). Storage and commodity markets. Cambridge University Press.

Working, H. (1949). The theory of price of storage. The American Economic Review, 39(6), $1254-1262$.

Wright, B. D. (2014). Global biofuels: Key to the puzzle of grain market behavior. Journal of Economic Perspectives, 28(1), 73-98.

Wright, B. D. and Williams, J. C. (1982). The economic role of commodity storage. The Economic Journal, 92(367), 596-614.

Wright, B. D. and Williams, J. C. (1984). The welfare effects of the introduction of storage. The 
Quarterly Journal of Economics, 99(1), 169-192. 